\title{
Low-dose creatine supplementation enhances fatigue resistance in the absence of weight gain
}

\author{
Authors: E.S. Rawson, M.J. Stec, S.J. Frederickson, and \\ M.P. Miles
}

This is the postprint version of an article published by Elsevier in Nutrition on April 2011. The published version can be found at http://dx.doi.org/10.1016/j.nut.2010.04.001.

Rawson ES, MJ Stec, SJ Frederickson, and MP Miles. Low-dose creatine supplementation enhances fatigue resistance in the absence of weight gain. Nutrition, 27:451-455, 2011. http://dx.doi.org/10.1016/j.nut.2010.04.001

Made available through Montana State University's $\underline{\text { ScholarWorks }}$ scholarworks. montana.edu 


\title{
Low-dose creatine supplementation enhances fatigue resistance in the absence of weight gain
}

Eric S. Rawson Ph.D.; Department of Exercise Science, Bloomsburg University, Bloomsburg, Pennsylvania, USA

Michael J. Stec B.S.; Department of Exercise Science, Bloomsburg University, Bloomsburg, Pennsylvania, USA

Sara J. Frederickson M.S.; Department of Health and Human Development, Montana State University, Bozeman, Montana, USA

Mary P. Miles Ph.D.; Department of Health and Human Development, Montana State University, Bozeman, Montana, USA

\begin{abstract}
Objective: We examined the effects of $6 \mathrm{wk}$ of low-dose creatine supplementation on body composition, muscle function, and body creatine retention.
\end{abstract}

Methods: Twenty healthy men and women $(21 \pm 2 \mathrm{y}$ old $)$ were randomized to receive creatine $\left(0.03 \mathrm{~g} \cdot \mathrm{kg}^{-1} \cdot \mathrm{d}^{-1} ; n=10,4\right.$ women $)$ or placebo $(n=$ 10,4 women) for $6 \mathrm{wk}$ in a double-blind placebo-controlled fashion. Participants were tested on two occasions before supplementation to establish a reliable baseline, and then were retested after supplementation. Testing included body composition, maximal strength (three-repetition maximal concentric knee extension at 180 degrees/s), muscle fatigue (five sets of 30 concentric knee extensions at 180 degrees/s), and plasma creatine concentration.

Results: There were no significant differences in body mass, fat-free mass, fat mass, body fat percentage, total body water, or maximal strength in either group from before to after supple-mentation (all $P>0.05$ ). After supplementation, plasma creatine increased significantly in the creatine group $(+182 \%, P=0.03)$, with no difference in the placebo group. Compared with baseline values, creatine-supplemented volunteers were more resistant to fatigue during sets $2(7 \%), 3(9 \%), 4(9 \%)$, and $5(11 \%)($ all $P<0.05)$. In placebo-supplemented participants, there was no improvement in fatigue resistance during sets $2(0 \%), 3(1 \%), 4(0 \%)$, and $5(-1 \%)$ (all $P>0.05)$.

Conclusion: Ingesting a low dose $(\approx 2.3 \mathrm{~g} / \mathrm{d})$ of creatine for $6 \mathrm{wk}$ significantly increased plasma creatine concentration and enhanced resistance to fatigue during repeated bouts of high-intensity contractions.

\section{Introduction}

Creatine continues to be a popular dietary supplement, with prevalence of use as high as $75 \%$ in some sports. Creatine ingestion and the subsequent increase in skeletal muscle creatine content may result in enhanced resistance to fatigue during intense exercise or increased lean body mass. Increased muscle creatine and phosphocreatine with oral creatine ingestion can be accomplished using two different approaches. In the first method, a "loading" dose of creatine, usually about 20 to $25 \mathrm{~g} / \mathrm{d}$ $\left(0.3 \mathrm{~g} \cdot \mathrm{kg}^{-1} \cdot \mathrm{d}^{-1}\right)$, for 5 to $7 \mathrm{~d}$ is ingested [1]. In the second method, lower doses of creatine, usually about 2 to $5 \mathrm{~g} / \mathrm{d}(0.03 \mathrm{~g}$ $\left.\cdot \mathrm{kg}^{-1} \cdot \mathrm{d}^{-1}\right)$, for about $4 \mathrm{wk}$ are ingested. This second protocol was based on the seminal work by Hultman et al. [1] who demon-strated that low doses of creatine supplementation could increase muscle creatine levels given adequate time. However, the minimal amount of creatine to have an effect (i.e., increased muscle creatine) and whether or not this can influence performance have not been clearly defined.
Although many drugs have a rapid onset of action, nutrients such as creatine have a delayed onset of action, because it must accumulate in skeletal muscle over time to exert its effect. Subsequently, any increase in muscle creatine after supplementation is a function of dose and duration. Although the commonly used high-dose creatine loading protocol $(20 \mathrm{~g} / \mathrm{d}$ for $5 \mathrm{~d}$ ) results in about a $20 \%$ to $25 \%$ increase in muscle creatine, the majority of the ingested creatine is excreted in the urine. For example, Rawson et al. [2] previously reported that during high-dose creatine ingestion ( $20 \mathrm{~g} / \mathrm{d}$ for $5 \mathrm{~d}$ ), about $47 \%$ can be recovered in the urine. In this investigation, nearly $50 \%$ of the ingested creatine was lost in the urine by day 3 of supplementation [2]. Similarly, Law et al. [3] reported $48 \%$ and 55\% urinary creatine excretions on days 3 and 6 of a typical creatine loading protocol $(20 \mathrm{~g} / \mathrm{d}$ for $5 \mathrm{~d})$. Recently, Sale et al. [4] reported that $20 \mathrm{~g}$ of creatine ingestion per day in frequent low doses $(20 \mathrm{~g} / \mathrm{d}$ in $20 \mathrm{1-g}$ doses) or a more traditional loading protocol $(20 \mathrm{~g} / \mathrm{d}$ in four $5-\mathrm{g}$ 
doses) resulted in $49 \%$ and $62 \%$ of the creatine being excreted, respectively. Although these investigators were able to modify body creatine retention by altering dosing frequency throughout the day, the majority of creatine was still excreted in the urine.

Some groups have reported that lower doses of creatine can be ergogenic [5,6], although others have reported no effect $[7,8]$. These discordant findings likely resulted from differences in supplementation duration, training status of the participants, creatine formulation, and exercise test selection (e.g., single bout versus repeated bouts). A gap in the literature exists regarding the effects of low-dose creatine ingestion on high-intensity exercise performance and body composition when dosing is based on body size and administered over a period of time that would allow sufficient muscle uptake. The purpose of the present study was to examine the effects of low-dose creatine supple-mentation on body composition, muscle function, and body creatine retention. We hypothesized that very low-dose creatine ingestion, when ingested over a sufficient period, would improve muscle function.

\section{Materials and methods}

Experimental design

This study was conducted in the Department of Exercise Science at Bloomsburg University (Bloomsburg, PA, USA). On visits 1 and 2, participants completed anthropometric/body composition, muscle strength, and muscle fatigue tests and a blood sample was obtained. Visits 1 and 2 occurred $7 \mathrm{~d}$ apart and were used to establish reliable baseline measurements. Participants then ingested creatine or placebo supplements for $6 \mathrm{wk}$. After the supplementation phase, participants repeated the anthropometric/body composition, muscle strength, and muscle fatigue tests, and a blood sample was obtained. Testing was conducted at the same time of day for all three visits ( $\pm 1 \mathrm{~h}$ ), and subjects reported to the laboratory in a postprandial state.

\section{Subjects}

Twenty non-vegetarian subjects ( 12 men, 8 women) recruited from the Bloomsburg area completed the study. All participants read and signed an informed consent document approved by the Bloomsburg University institutional review board before participation. Subjects were instructed to maintain similar habitual physical activity and dietary behaviors for the duration of the study. Individuals who had previously ingested creatine supplements were permitted to participate in this investigation if they had not ingested creatine supplements within the previous $6 \mathrm{wk}$. Descriptive characteristics of the subjects are presented in Table 1.

\section{Supplementation}

Participants were randomized to a creatine or placebo group using a random number table, and supplements were administered in a double-blind, placebocontrolled manner. Subjects ingested $0.03 \mathrm{~g}$ of creatine (NutraSense Company, Shawnee Mission, KS, USA) or placebo per kilogram of body weight per day for $6 \mathrm{wk}$ (range 1.7-2.9 g/d). Similar supplementation protocols have been previ-ously shown to significantly increase muscle creatine levels [1]. Participants were instructed to ingest the supplements with food because this enhances body creatine retention [9]. Compliance, assessed by return of empty supplement containers, was greater than $99 \%$.

\section{Table 1}

Participant characteristics*

\begin{tabular}{lllll}
\hline & Age $(\mathrm{y})$ & $\begin{array}{l}\text { Height } \\
(\mathrm{cm})\end{array}$ & $\begin{array}{l}\text { Body mass } \\
(\mathrm{kg})\end{array}$ & $\begin{array}{l}\text { BMI } \\
\left(\mathrm{kg} / \mathrm{m}^{2}\right)\end{array}$ \\
\hline $\begin{array}{c}\text { Creatine group }(n=10,4 \\
\begin{array}{c}\text { women }) \\
\text { Placebo group }(n=10,4 \\
\text { women })\end{array}\end{array}$ & $21.0 \pm 2.3$ & $171.4 \pm 10.1$ & $74.3 \pm 14.0$ & $25.1 \pm 3.1$ \\
\hline
\end{tabular}

BMI, body mass index

* Data are presented as mean \pm SD.
The creatine used in this study was manufactured by Ferro-Pfanstiehl Laboratories (Waukegan, IL, USA). Every lot of Ferro-Pfanstiehl creatine is tested with high-performance liquid chromatography to ensure purity, is certified Kosher, and each shipment of creatine is accompanied with a certificate of analysis, which includes information on loss on drying, appearance, residue ignition, heavy metals, assay, dicyandiamide, creatinine, identity, arsenic, Escherichia coli, Salmonella, Staphylococcus aureus, yeasts and molds, and coli-forms. All were below acceptable limits. An external validation study reported that Ferro-Pfanstiehl creatine contains $100 \%$ of what is claimed on the label, and high-performance liquid chromatogram showed no other peaks besides creatine, which indicates no contaminants [10].

\section{Blood collection and analysis}

On visits 1,2 , and 3, a fasting blood draw was taken from an antecubital vein in a Vacutainer containing $\mathrm{K}_{2}$ ethylenediaminetetra-acetic acid, centrifuged, frozen, and stored for later analysis. The final sample after supplementation was obtained about $12 \mathrm{~h}$ after the last supplement dose. According to the recom-mendation of the manufacturer of the creatine assay, plasma samples were thawed and filtered to eliminate absorption interference by large proteins. Plasma was added to $10-\mathrm{kD}$ spin columns (BioVision Research Products, Moun-tain View, CA, USA) and centrifuged for $20 \mathrm{~min}$ at $14000 \times \mathrm{g}$. Creatine concen-tration of the filtrate was assayed in duplicate using a commercially available enzymatic assay (K635-100, BioVision Research Products). The endproduct of this assay, oxidized carnosine, was measured spectrophotometrically in a 96-well plate at $570 \mathrm{~nm}$ using a $\mu$ Quant Universal microplate spectrophotometer (Bio-Tek Instruments, Winooski, VT, USA). Plasma creatine from each of the three time points was assessed in duplicate within a single run of the assay. The average intra-assay coefficient of variation for the assay was $3.5 \%$.

\section{Anthropometry and body composition}

The BC-418 8-contact electrode bioimpedance analyzer (Tanita Corporation of America, Inc., Arlington Heights, IL, USA) was used to assess body mass and body composition on visits 1 and 2. Participants were instructed to wear a t-shirt and shorts and to adhere to the following pretesting guidelines: 1) no physical exercise within $12 \mathrm{~h}$ of the scheduled test; 2 ) no eating or drinking within $8 \mathrm{~h}$ of the test; 3 ) empty bladder within 30 min of the test; and 4) no alcohol consumption within $48 \mathrm{~h}$ of the test. The Tanita analyzer allows estimates of total lean body mass and fat mass and of appendicular and trunk lean and fat masses. Recent data have shown that assessments of appendicular, trunk, and total lean masses using the Tanita analyzer correlate highly with lean mass using dual X-ray absorptiometry $(r \geq 0.95)$ [11]. In addition, bioimpedance has been used to detect increases in fat-free mass [12] and total body water [13] after creatine supple-mentation. Height was measured with a wall-mounted stadiometer.

\section{Maximal strength and fatigue tests}

Maximal strength and muscle fatigue were assessed in random order with a 5min rest between tests. Muscle strength was assessed with a three-repetition maximal (3-RM) concentric knee extension test at 180 degrees/s (Biodex Medical Systems, Shirley, NY, USA). The highest peak torque of the three repetitions was used to represent muscle strength in the analysis. Muscle fatigue was assessed with five sets of 30 concentric knee extensions at 180 degrees/s with a 60 -s rest between sets (Biodex Medical Systems). Each knee extension began with the knee at 90 degrees of flexion, continued to a point of full knee extension, and concluded with the leg actively returned (500 degrees/s) to the starting position. During the exercise test, participants folded their arms across their chests, and waist, torso, and thigh belts were used to decrease unnecessary movement. For the fatigue test, the 30 peak torques for each set were summed to create a fatigue score for each of the five sets. Relative fatigue was determined by calculating the difference between the sum of 30 peak torques for each set and set 1 , dividing by set 1 , and multiplying by 100 (e.g. [sum of peak torques set 1 - sum of peak torques set 2 ]/sum of peak torques set $1 \mathrm{X}$ 100).

\section{Statistical analysis}

Reliability of the 3-RM strength, muscle fatigue, and body composition tests from visit 1 to visit 2 was assessed with an intraclass correlation coefficient and analysis of variance (ANOVA). Participant characteristics were compared using independent $t$ tests. A repeated measures ANOVA was used to compare the pattern of change in blood creatine, body composition, and maximal knee extensor strength from before to after supplementation. A three-factor (group by sets by time) repeated measures ANOVA was used to compare relative muscle fatigue between the creatine and placebo groups. Tukey's post hoc tests were used to locate differences when ANOVA revealed a significant interaction. The level of significance was set a priori at $P \leq 0.05$. 
Table 2

Anthropometry and body composition*

\begin{tabular}{|c|c|c|c|c|c|}
\hline & \multicolumn{2}{|l|}{ Creatine } & \multicolumn{2}{|l|}{ Placebo } & \multirow[t]{2}{*}{$P$ for $\mathrm{G} \times \mathrm{T}$} \\
\hline & Before supplementation & After supplementation & Before supplementation & After supplementation & \\
\hline $\mathrm{BM}(\mathrm{kg})$ & $74.3 \pm 14.0$ & $73.9 \pm 13.8$ & $76.5 \pm 7.1$ & $76.6 \pm 7.2$ & 0.50 \\
\hline FFM (kg) & $60.5 \pm 13.5$ & $60.0 \pm 14.0$ & $60.3 \pm 10.9$ & $62.2 \pm 11.5$ & 0.20 \\
\hline FM (kg) & $13.7 \pm 5.3$ & $13.9 \pm 5.6$ & $16.2 \pm 7.1$ & $14.5 \pm 5.6$ & 0.29 \\
\hline $\mathrm{BF} \%$ & $18.8 \pm 7.5$ & $19.2 \pm 8.3$ & $21.5 \pm 9.8$ & $19.5 \pm 9.1$ & 0.24 \\
\hline TBW (kg) & $44.3 \pm 9.9$ & $43.9 \pm 10.2$ & $44.1 \pm 7.9$ & $45.5 \pm 8.4$ & 0.19 \\
\hline
\end{tabular}

BF\%, body fat percentage; BM, body mass; FFM, fat-free mass; FM, fat mass; $\mathrm{G} \times \mathrm{T}$, group-by-time interaction; TBW, total body water

$*$ Data are presented as mean $\pm \mathrm{SD}$.

\section{Results}

There were no significant differences between visits 1 and 2, and reliability $(R)$ of the 3-RM strength and muscle fatigue tests were 0.91 and 0.86 , respectively. This is similar to previous reports from our laboratory [14]. There were no significant differences in any anthropometric or body composition measurements from visit 1 to visit 2 and intraclass correlation coefficients were high (body mass, $R=0.99$; body mass index, $R=0.99$; fat-free mass, $R=0.99$; fat mass, $R=0.97$; percentage of body fat, $R=0.97$; total body water, $R=0.99$ ).

There were no significant differences in participant characteristics (i.e., age, height, body mass, body mass index) between the creatine and placebo groups (Table 1 ). There were no differences in body composition (body mass, fat-free mass, fat mass, percentage of body fat, or total body water) from before to after supplementation in either group (Table 2).

Plasma creatine increased significantly from before to after supplementation in creatine-supplemented subjects $(P=0.03$, creatine group $+182 \%$, range $0-129 \mu \mathrm{mol} / \mathrm{L}$; Fig. 1 ). There was no effect of group $(P=0.51)$, no effect of time $(P=0.15)$, and no groupby-time interaction $(P=0.30)$ in the analysis of knee extensor strength, indicating that creatine supplementation had no effect on maximal strength (Fig. 2). There was a significant

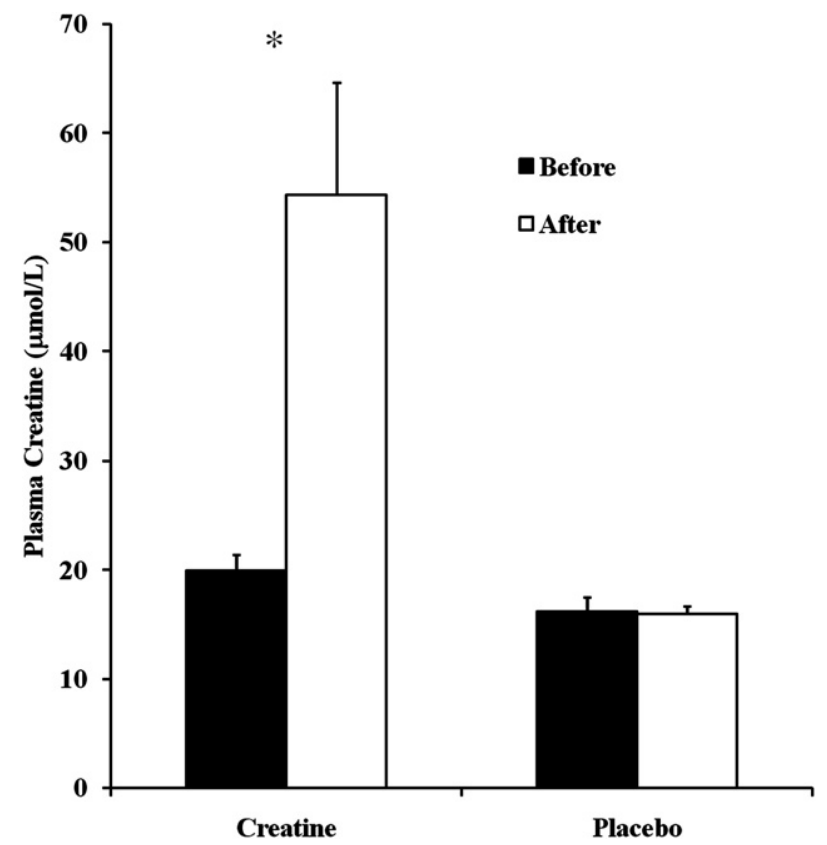

Fig. 1. Plasma creatine before and after $6 \mathrm{wk}$ of low-dose creatine $\left(0.03 \mathrm{~g} \mathrm{~kg}^{-1} \mathrm{~d}^{-1}\right)$ or placebo supplementation. ${ }^{*}$ Significant increase from before supplementation. effect of sets $(P<0.001)$ and a significant group-by-sets-by-time interaction $(P=0.03)$ in the analysis of knee extensor fatigue. Post hoc analysis indicated that muscle fatigue increased from set 1 through set 5 in both groups and that creatine-supplemented participants were more resistant to fatigue after supplementation (7\% in set $2,9 \%$ in set $3,9 \%$ in set 4 , and $11 \%$ in set 5 ; Fig. 3A,B). There were no changes in muscle fatigue in the placebo group from before to after supplementation.

\section{Discussion}

We investigated the effects of 6 wk of low-dose creatine supplementation $\left(0.03 \mathrm{~g} \cdot \mathrm{kg}^{-1} \cdot \mathrm{d}^{-1}\right)$ on body composition, plasma creatine, knee extensor strength, and knee extensor muscle fatigue. Creatine supplementation had no effect on body composition or strength but increased plasma creatine and, in support of our hypothesis, enhanced resistance to fatigue. Our data indicate that the ingestion of approximately $2.3 \mathrm{~g}$ of creatine per day for $6 \mathrm{wk}$ can increase body creatine retention and enhance fatigue resistance during repeated sets of high-intensity contractions with no increase in body mass. Data from other groups $[5,6]$ and the present study indicate that a traditional creatine loading protocol (about $20 \mathrm{~g} / \mathrm{d}$ for $5 \mathrm{~d}$ ) may not be necessary to enhance resistance to fatigue.

The finding that low-dose creatine supplementation improves muscle function is consistent with some [5,6], but not all [7,8], studies. Data from Hoffman et al. [5] and Selsby et al. [6], who reported that lower-dose longer-term creatine ingestion can decrease muscle fatigue with no increase in body mass, are in support of our findings. Despite the differences in supplement dosing strategies ( $94 \mathrm{~g}$ in $42 \mathrm{~d}$ in present study, $36 \mathrm{~g}$ in $6 \mathrm{~d}$ in Hoffman et al. [5], $25 \mathrm{~g}$ in $10 \mathrm{~d}$ in Selsby et al. [6]), these studies indicate that the loading phase is unnecessary to enhance fatigue resistance without weight gain. In contrast, Eckerson et al. [7] and Thompson et al. [8] found no effects of creatine supplementation on muscle function during longer-duration exercise tests ( $\approx 1$ t $0 \approx 13 \mathrm{~min}$ ) and without repeated bouts, which may explain the lack of an ergogenic effect. In addition, Thompson et al. [8] were unable to demonstrate increased muscle creatine from before to after supplementation using magnetic resonance spectroscopy.

Although not found in every case, many investigators have noted an increase in body mass after creatine ingestion [3,7, 1519]. It is not known if this increase in body mass is tempo-rary, or if it is maintained as long as muscle creatine levels are elevated. Rawson et al. [18] previously reported a case study of a high responder to creatine supplementation who presented with increased muscle phosphocreatine (23\%) and increased body mass ( $2 \mathrm{~kg}$ ) $30 \mathrm{~d}$ after discontinuing creatine ingestion. In the present study, plasma creatine increased (182\%) indicating increased body creatine levels, but there was no significant 


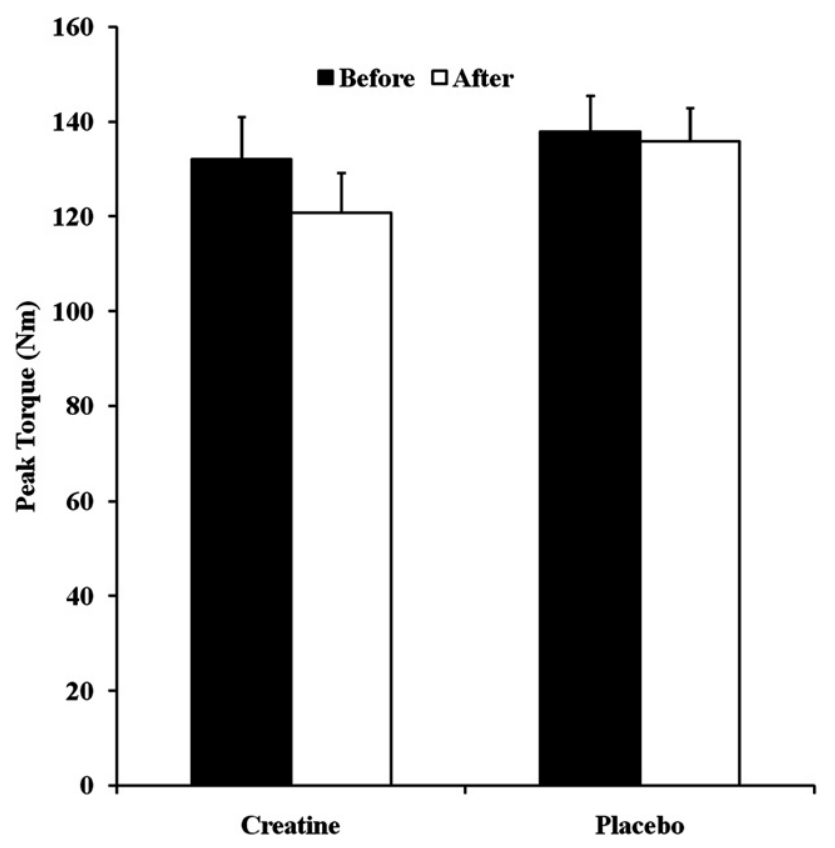

Fig. 2. No change in isokinetic knee extensor strength after 6 wk of low-dose $(0.03$ $\mathrm{g} \cdot \mathrm{kg}^{-1} \cdot \mathrm{d}^{-1}$ ) creatine supplementation.

increase in body mass or total body water. Potentially, the increased total body water associated with creatine supplementation [20] does not occur with low-dose, longer-duration creatine supplementation. Alternatively, the increase in body water and body mass seen in high-dose ( $>20 \mathrm{~g} / \mathrm{d})$ creatine supplementation studies (without concurrent resistance training) may subside if supplementation is continued over several weeks. These questions can only be answered in a study that compares different dosing protocols and assesses body composition at multiple time points over several weeks.

The average adult has about $120 \mathrm{~g}$ of muscle creatine. Creatine loading typically provides $100 \mathrm{~g}$ ( $20 \mathrm{~g} / \mathrm{d}$ for $5 \mathrm{~d}$ ) above dietary intake, yet increases muscle creatine levels only by about $23 \mathrm{~g}$ $(\approx 20 \%)$. This calculation and previous data on urinary creatine excretion during creatine ingestion [2-4] demonstrate that, although effective at increasing muscle creatine, a high-dose loading phase may not be necessary. The optimal creatine supplementation protocol should increase muscle creatine, minimize creatinuria, and maintain elevated muscle creatine during natural creatine degradation to creatinine. We based the creatine dosing protocol used in the present study on the work of Hultman et al. [1] who demonstrated a $20 \%$ increase in muscle creatine when ingesting $20 \mathrm{~g}$ of creatine per day for $6 \mathrm{~d}$ or $3 \mathrm{~g}$ of creatine per day $\left(0.03 \mathrm{~g} \cdot \mathrm{kg}^{-1} \cdot \mathrm{d}^{-1}\right)$ for $28 \mathrm{~d}$. Based on this work, the fact that creatine loading produces marked creatinuria $(\approx 50 \%$ of supplement [10 $000 \mathrm{mg}$ ] excreted) [2-4], and given that nutrients such as creatine have a delayed onset of action and must accumulate in skeletal muscle over time to exert an effect, we examined a low-dose longer-term supplementation protocol. According to Harris et al. [21,22], we estimate there was about 113 $\mathrm{g}$ of skeletal muscle creatine in the participants in our study (body mass $\approx 74 \mathrm{~kg}$ ). Further, the commonly seen increase of about 25 $\mathrm{mmol} / \mathrm{kg}$ of dry matter after creatine supplementation [22] is equivalent to about $23 \mathrm{~g}$ of creatine. The $20 \%$ increase in muscle creatine reported by Hultman et al. [1] after high-dose short-term $(20 \mathrm{~g} / \mathrm{d}$ for $6 \mathrm{~d})$ or low-dose longer-term $3-\mathrm{g} / \mathrm{d}(0.03 \mathrm{~g} / \mathrm{kg}$ for $28 \mathrm{~d})$ supplementation represents about $17 \%$ of ingested supplemental creatine. In the present study, $23 \mathrm{~g}$ of supplemental creatine (17\%) would have been consumed after about $10 \mathrm{~d}$. Previously, Hultman et al. [1] demonstrated greater muscle creatine uptake during the first $14 \mathrm{~d}$ of low-dose $\left(0.03 \mathrm{~g} \cdot \mathrm{kg}^{-1} \cdot \mathrm{d}^{-1}\right)$ supplementation versus the last $14 \mathrm{~d}$ ( $30 \%$ or $14 \mathrm{~g}$ versus $12 \%$ or $5 \mathrm{~g}$ ). Thus, although our dosing protocol was sufficient to increase body creatine retention and enhance resistance to fatigue, it is possible that this could have been achieved by ingesting a similar low dose, but for a shorter period. Two variables influence the estimation of body creatine retention that cannot be accounted for in the present study. First, dietary creatine was not assessed, so we cannot know how much creatine was ingested through dietary sources. It has been suggested that dietary creatine intake is $2 \mathrm{~g} / \mathrm{d}$ [23], but evidence and details about dietary creatine intake in different population subgroups (e.g., strength power athletes, endurance athletes, patient populations) are lacking. Future research should examine dietary creatine intake before and during supplementation, so the true minimal dose of supplemental creatine needed to enhance fatigue resistance without weight gain can be deter-mined. Second, the rate of creatine degradation to creatinine, which is normally estimated at $2 \mathrm{~g} / \mathrm{d}$ [24], was not assessed in this
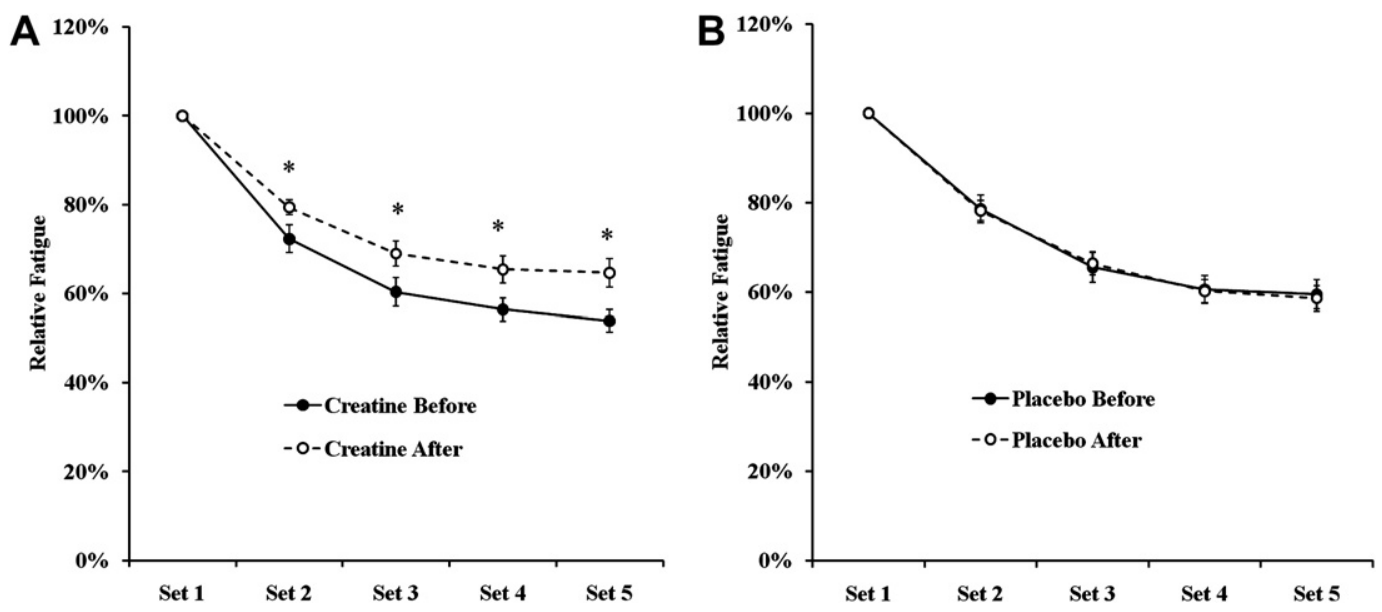

Fig. 3. (A) Improvement in fatigue resistance after $6 \mathrm{wk}$ of low-dose $\left(0.03 \mathrm{~g} \mathrm{~kg}^{-1} \mathrm{~d}^{-1}\right)$ creatine supplementation. (B) No change in fatigue resistance after $6 \mathrm{wk}$ of placebo supplementation. ${ }^{*}$ Significant improvement from before supplementation. 
this study. It has been suggested that creatine supplementation must exceed creatine degradation for supplemental creatine to accumulate in skeletal muscle [1], but this cannot be determined from the present study. In addition, this study was not powered to assess sex differences in response to low-dose creatine ingestion. It has been reported that women have a smaller increase in fat-free mass compared with men subsequent to short-term high-dose creatine supplementation [25], but differential responses between the sexes cannot be addressed from the current study.

The present study demonstrates the efficacy of low-dose creatine supplementation on improving fatigue resistance. The dose used in this study was approximately $2.3 \mathrm{~g} / \mathrm{d}$ of creatine $\left(0.03 \mathrm{~g} \cdot \mathrm{kg}^{-1} \cdot \mathrm{d}^{-1}\right)$, which appears to be the lowest effective dose found in the current literature. By extending the duration of the supplementation period beyond the typical 5-d loading period, we were able to improve fatigue resistance with a relatively low dose of creatine. In addition, most research on creatine has examined the effects of a fixed dose (e.g., $5 \mathrm{~g} / \mathrm{d}, 20 \mathrm{~g} / \mathrm{d}$ ) without regard to body size. Because more than 95\% of creatine is stored in skeletal muscle [24], it makes sense to dose based on some measurement of body size (e.g., body mass, fat-free mass). An additional unique finding of the present study is the absence of weight gain or increases in total body water. These may be viewed as beneficial effects in athletic populations for whom weight gain is undesirable. Future research should examine the effects of different doses of creatine supplementation with body composition and muscle function outcomes assessed at multiple time points in an effort to determine the minimal effective dose.

\section{Acknowledgments}

The authors thank the research participants for their dedication.

\section{References}

[1] Hultman E, Söderlund K, Timmons JA, Cederblad G, Greenhaff PL. Muscle creatine loading in men. J Appl Physiol 1996;81:232-7.

[2] Rawson ES, Clarkson PM, Price TB, Miles MP. Differential response of muscle phosphocreatine to creatine supplementation in young and old subjects. Acta Physiol Scand 2002;174:57-65.

[3] Law YL, Ong WS, GillianYap TL, Lim SC, Von Chia E. Effects of two and five days of creatine loading on muscular strength and anaerobic power in trained athletes. J Strength Cond Res 2009;23:906-14.

[4] Sale C, Harris RC, Florance J, Kumps A, Sanvura R, Poortmans JR. Urinary creatine and methylamine excretion following $4 \times 5 \mathrm{~g} \times \mathrm{day}(-1)$ or $20 \times 1 \mathrm{~g} \times$ day $(-1)$ of creatine monohydrate for 5 days. J Sports Sci 2009;27:759-66.

[5] Hoffman JR, Stout JR, Falvo MJ, Kang J, Ratamess NA. Effect of low-dose, short-duration creatine supplementation on anaerobic exercise performance. J Strength Cond Res 2005;19:260-4.

[6] Selsby JT, DiSilvestro RA, Devor ST. Mg2+-creatine chelate and a low-dose creatine supplementation regimen improve exercise performance. Strength Cond Res 2004;18:311-5.

[7] Eckerson JM, Bull AA, Moore GA. Effect of thirty days of creatine supplementation with phosphate salts on anaerobic working capacity and body weight in men. J Strength Cond Res 2008;22:826-32.

[8] Thompson CH, Kemp GJ, Sanderson AL, Dixon RM, Styles P, Taylor DJ, et al. Effect of creatine on aerobic and anaerobic metabolism in skeletal muscle in swimmers. Br J Sports Med 1996;30:222-5.

[9] Steenge GR, Simpson EJ, Greenhaff PL. Protein- and carbohydrate-induced augmentation of whole body creatine retention in humans. J Appl Physiol 2000;89:1165-71.

[10] Persky AM, Hochhaus G, Brazeau GA. Validation of a simple liquid chromatography assay for creatine suitable for pharmacokinetic applications, determination of plasma protein binding and verification of percent labeled claim of various creatine products. J Chromatogr B Analyt Technol Biomed Life Sci 2003;794:157-65.

[11] Pietrobelli A, Rubiano F, St-Onge MP, Heymsfield SB. New bioimpedance analysis system: improved phenotyping with whole-body analysis. Eur J Clin Nutr 2004;58:1479-84.

[12] Kilduff LP, Lewis S, Kingsley MI, Owen NJ, Dietzig RE. Reliability and detecting change following short-term creatine supplementation: comparison of two-component body composition methods. J Strength Cond Res 2007;21:378-84.
[13] Kutz MR, Gunter MJ. Creatine monohydrate supplementation on body weight and percent body fat. J Strength Cond Res 2003;17:817-21.

[14] Rawson ES. Enhanced fatigue resistance in older adults during repeated sets of intermittent contractions. J Strength Cond Res 2010;24:251-6.

[15] Burke DG, Silver S, Holt LE, Smith Palmer T, Culligan CJ, Chilibeck PD. The effect of continuous low dose creatine supplementation on force, power, and total work. Int J Sport Nutr Exerc Metab 2000;10:235-44.

[16] Eckerson JM, Stout JR, Moore GA, Stone NJ, Nishimura K, Tamura K. Effect of two and five days of creatine loading on anaerobic working capacity in women. J Strength Cond Res 2004;18:168-73.

[17] Herda TJ, Beck TW, Ryan ED, Smith AE, Walter AA, Hartman MJ, et al. Effects of creatine monohydrate and polyethylene glycosylated creatine supplementation on muscular strength, endurance, and power output. J Strength Cond Res 2009;23:818-26.

[18] Rawson ES, Persky AM, Price TB, Clarkson PM. Effects of repeated creatine supplementation on muscle, plasma, and urine creatine levels. J Strength Cond Res 2004;18:162-7.

[19] Syrotuik DG, Bell GJ, Burnham R, Sim LL, Calvert RA, MacLean IM. Absolute and relative strength performance following creatine monohydrate supplementation combined with periodized resistance training. J Strength Cond Res 2000;14:182-90.

[20] Powers ME, Arnold BL, Weltman AL, Perrin DH, Mistry D, Kahler DM, et al. Creatine supplementation increases total body water without altering fluid distribution. J Athletic Train 2003;38:44-50.

[21] Harris RC, Hultman E, Nordesjö LO. Glycogen, glycolytic intermediates and high-energy phosphates determined in biopsy samples of musculus quadriceps femoris of man at rest. Methods and variance of values. Scand J Clin Lab Invest 1974;33:109-20.

[22] Harris RC, Söderlund K, Hultman E. Elevation of creatine in resting and exercised muscle of normal subjects by creatine supplementation. Clin Sci (Colch) 1992;83:367-74.

[23] Balsom PD, Söderlund K, Ekblom B. Creatine in humans with special reference to creatine supplementation. Sports Med 1994;18:268-80.

[24] Walker JB. Creatine: biosynthesis, regulation, and function. Adv Enzymol Relat Areas Mol Med 1979;50:177-242.

[25] Mihic S, MacDonald JR, McKenzie S, Tarnopolsky MA. Acute creatine loading increases fat-free mass, but does not affect blood pressure, plasma creatinine, or CK activity in men and women. Med Sci Sports Exerc 2000;32:291-6. 